\title{
A atuação da família no desenvolvimento das habilidades do futuro músico
}

Miriam Grosman

(UFRJ)

Resumo: O presente trabalho tem por objetivo demonstrar a importância do papel da família no desenvolvimento das habilidades musicais, particularmente na infância, apresentando resultados de pesquisas e posições adotadas por especialistas de comprovada competência. Tendo por base esse conhecimento, será possível redimensionar ou modificar conceitos e pensamentos em geral que definem e envolvem o potencial musical do indivíduo.

Palavras-chave: ensino e família; habilidades na infância; música: ensino e motivação

THE ROLE OF FAMILY ON THE DEVELOPMENT OF MUSICAL SKILLS OF THE FUTURE MUSICIAN

\begin{abstract}
The purpose of this work is to demonstrate the importance of the role of the family on the development of musical skills, particularly in childhood, presenting results based on research and opinions adopted by specialists of proven competence. Having this knowledge as a base, it will be possible to redimension or to change the general concepts and thoughts which define and evolve the musical potential of the individual.
\end{abstract}

Keywords: family and education; skills in childhood; motivation and teaching 


\section{1 - CONSIDERAÇÕES GERAIS}

É muito comum ouvirmos referências a crianças que são consideradas "musicais". De um modo geral, pode significar que existe um potencial ainda não trabalhado, não realizável, mas que mostram possibilidades de expressar algo "musical".

De acordo com várias pesquisas, A. Kemp e J. Mills (2002, p. 3) afirmam que os sinais do "potencial", na verdade, são manifestações de uma aquisição musical dentro de uma aprendizagem formal ou informal e, portanto, revelam experiências prévias.

Segundo estes mesmos autores, todas as crianças possuem algum potencial, umas mais do que outras, ou em diferentes maneiras ou formas.

Seja como for, Howe e Cattell (apud Kemp e Mills, 2002) afirmam que qualquer habilidade depende basicamente de três fatores: habilidade propriamente dita, personalidade e motivação. Ressaltam ainda, que mesmo os testes elaborados para detectar habilidades, em geral acabam exigindo ou revelando uma experiência prévia.

Considerando nossas experiências artísticas e pedagógicas, verificamos que são vários os fatores que influenciam favoravelmente a trajetória de um pianista que alcança um nível de excelência profissional. Dentre as aquisições necessárias e indispensáveis, podemos mencionar: domínio técnico, amplo repertório solista, camerista e orquestral, conhecimento estilístico, análise, leitura, conhecimento que abrange outras áreas, além, naturalmente, de características pessoais que incluem determinação e disciplina.

No entanto, toda essa aquisição não seria viável sem o estímulo do meio ambiente, talvez tão ou mais importante do que as chamadas qualidades inatas. Neste trabalho, focalizamos a motivação dentro do ambiente familiar como um fator decisivo para o possível sucesso da carreira musical.

Presenciei ainda jovem, durante minha formação musical, embora sem uma visão crítica ou analítica, o quanto a família de um estudante de música pode influenciar na sua trajetória, podendo determinar o sucesso ou o fracasso, dependendo do grau ou nível de atuação. 
Essa posição vem sendo reforçada em informações obtidas em publicações de periódicos e livros, contatos informais e mesmo em observações ocasionais.

A minha própria experiência pode servir como exemplo para a abertura do tema. Algumas gerações foram contempladas com uma educação em que a música era praticamente uma atividade obrigatória quando constatamos, por exemplo, a presença de um piano em quase todas as residências de classe média no Brasil. No entanto, mesmo proporcionando educação musical aos filhos, muitos pais não demonstravam perspectivas em uma carreira profissional. Apreciavam a arte musical e incentivavam as atividades nas quais os jovens pudessem adquirir uma formação cultural mais completa, sem, no entanto, direcioná-las profissionalmente.

Quanto aos pais que acreditavam ou geravam expectativas num futuro profissional, estavam sempre atentos ao desempenho e desenvolvimento musical de filhos, muitos dos quais viriam a se destacar no panorama musical nacional e internacional. Acompanhavam os filhos nas aulas, obrigavam-nos a uma disciplina de trabalho, e, especialmente, conduziam-nos aos melhores professores. O apoio familiar associado a professores capacitados sugere a hipótese de que este binômio seria fator decisivo no sucesso profissional e artístico do futuro pianista.

Acreditamos que esta hipótese possa também ser formulada em outras áreas; contudo, neste estudo será focalizada a relação entre o nível de desempenho de pianistas e a influência familiar.

\section{2 - O POTENCIAL DA CRIANÇA}

Bloom, Sloboda e Howe (apud Kemp e Mills, 2002) sugerem que o fator mais importante para o que denominamos "talento" da criança é o estímulo do meio ambiente, através do encorajamento, oportunidades apropriadas e apoio, inclusive financeiro. As experiências mais fortes e significativas tendem a ocorrer em casa, seja através do estímulo à performance, da audição de gravações ou mesmo da observação das diversas atividades musicais dentro do ambiente familiar. 
Kemp e Mills (2002) destacam a importância dos pais e professores na medida em que investem na criança, partindo de uma visão projetada no seu futuro musical. Afirmam, ainda, através de pesquisas e estudos correlacionados, que o "potencial musical" está sendo considerado como um fenômeno muito mais complexo, envolvendo um significativo número de fatores ao lado, evidentemente, das habilidades propriamente ditas musicais.

Partindo de tais premissas, acreditamos que esse potencial é um processo que ocorre em casa desde o nascimento até os primeiros anos de uma educação formal. Além disso, toma muitas formas no decorrer da formação musical e ocorre em diferentes níveis, dependendo da qualidade do meio ambiente, podendo ser mais ou menos propício e estimulante. Quando pais e professores atuam concomitantemente na motivação, afetam, de certa forma, a personalidade e o desenvolvimento do talento da criança.

De acordo com Gembris e Davidson (2002), os fatores genéticos também afetam os indivíduos, como por exemplo, maturidade e capacidade física e mental, embora segundo os mesmo autores, vários resultados de pesquisas apontam as habilidades musicais e seu desenvolvimento com base na interação entre as capacidades inatas e o meio ambiente.

Poderíamos apresentar diferentes 'ambientes', para que possamos entender melhor seu significado e influência, sejam eles os sistemas sócio-culturais, as instituições como a família e a escola ou os grupos. No caso específico deste trabalho, focalizamos especialmente a atuação da família no processo de desenvolvimento das habilidades musicais.

A frequência e duração das atuações podem variar de um extremo ao outro, e podem também ser compartilhadas, como nos casos onde membros da mesma família apresentaram diferentes reações ou resultados dentro de um mesmo meio ambiente e, portanto, afetados diferentemente.

De acordo com Plomin (apud Gembris e Davidson, 2002), o impacto do ambiente familiar no desenvolvimento do futuro músico pode se apresentar de três diferentes aspectos, atuando em conjunto, separadamente ou em diferentes proporções nas seguintes situações: 
1) Em uma atmosfera estimulante como, por exemplo, o estilo de vida da família, status profissional, interesses culturais e educação.

2) Em uma relação entre o meio social e a personalidade e temperamento do indivíduo. Nesse caso, a criança que apresentar uma característica de avidez em aprendizagem, pode adquirir e procurar mais oportunidades no seu meio ambiente dos que as que não tem.

3) Em seleções ou aproveitando oportunidades que o meio ambiente proporciona.

No entanto, Plomin (apud Gembris e Davidson, 2002) salienta que tais genótipos podem não ser sempre os mesmos durante a vida do indivíduo. Por exemplo, uma criança pode não apresentar avidez de conhecimento durante sua infância, o que poderá acontecer anos depois quando se tornar um adulto jovem.

Em todas as citadas situações, fica evidente que o fator motivação deve ser considerado como essencial para o desenvolvimento de habilidades e aquisição de conhecimento. Qualquer desenvolvimento requer forte motivação e este tem sido um tema explorado em recentes trabalhos sobre performance e formação musical .

Para Chaffin e Lemieux (2011), há forte evidência de uma poderosa contribuição do meio ambiente tanto para a motivação como para o desenvolvimento da excelência musical. A motivação seria, portanto, um dos vários e necessários componentes do talento musical e ainda não existem. segundo estes autores, fundamentos para afirmar a contribuição da genética.

McPherson \& Zimmerman (2002) sustentam a mesma posição quando afirmam que motivação intrínseca parece também ser essencial para o desenvolvimento das estratégias de estudo e admitem que a motivação das crianças para o estudo instrumental é, em grande parte, resultado do envolvimento dos pais no processo de aprendizagem. 


\section{3 - A CASA E A FAMÍLIA}

De acordo com Seckl (apud Gembris e Davidson, 2002), a influência do meio ambiente começa antes do nascimento e, segundo o mesmo autor, pode ter impacto até mesmo na saúde, tornando o indivíduo suscetível a doenças. Estudos revelam que bebês podem "ouvir" música e vozes semanas antes do nascimento, embora seja ainda difícil avaliar qual o tipo de estímulo que afetará o desenvolvimento posterior.

De acordo com Jean-Pierre Lecanuet (1996), estudos demonstraram que as experiências auditivas no período pré-natal podem resultar em algum tipo de aprendizagem em diferentes situações após o nascimento, ou seja, podem ocorrer efeitos após nascimento causados por exposição sonora pré-natal.

Parece ser muito clara a evidência do papel desempenhado pela família, que de acordo com Manfurzewska (apud Gembris e Davidson, 2002), através de análise detalhada de biografias de músicos poloneses, enfatizou o perfil familiar e chegou à conclusão de que os antecedentes familiares constituem o principal fator para a carreira do músico clássico. Este mesmo autor destaca dez importantes situações em que o ambiente doméstico-familiar pode influenciar decisivamente na carreira desses músicos:

1) Atitude dos pais centrada na educação musical da criança.

2) Organização e canalização dos interesses, tempo e atividades das crianças.

3) Crença e encorajamento de, pelo menos uma pessoa da família, no potencial do futuro músico.

4) Valorização da música na vida da família.

5) Ênfase na apreciação, gosto e prática das atividades musicais.

6) Oferecimento de prêmios e elogios.

7) Atmosfera positiva para as atividades musicais.

8) Seleção cuidadosa dos professores, assim como o monitoramento do desenvolvimento musical.

9) Suporte em vários níveis e articulação com profissionais e professores. 
10) Desejo de investir tempo considerável e esforço para as atividades musicais.

Resultados de vários estudos mostram que crianças com alto nível de desempenho musical são apoiadas principalmente pelos pais, especialmente até os 11 anos, de acordo com Davidson, Sloboda e Howes, (apud GEMBRIS e DAVIDSON, 2002). Esses autores sustentam que a importância do apoio é decisiva, enfatizando, ainda, que a excelência no desempenho é praticamente impossível sem o envolvimento dos pais, embora haja exemplos excepcionais de bem sucedidos músicos que receberam muito pouco apoio familiar.

\section{4 - O DESEMPENHO DOS PAIS NO DESENVOLVIMENTO DO TALENTO DOS FILHOS}

Não é desconhecido que as crianças pequenas aprendem não apenas através dos pais, mas também através da herança cultural do seu meio. Não é desconhecido também que as crianças estimuladas com elementos musicais em período anterior à linguagem verbal, e, dependendo do grau desse estímulo, podem despertar atração e desenvolvimento da musicalidade.

Segundo Sloboda and Davidson (1996), existem dois mitos sobre o que se pode denominar musicalidade de excelência. O primeiro deles revela que um alto nível de realização musical deve ser necessariamente raro; o segundo, que estes raros talentos são reconhecidos prematuramente. No entanto, os conceitos de habilidades tem sido revistos e podem ser vistos de diferentes maneiras.

Entrevistas com pais de indivíduos "talentosos" forneceram informações para Sloane (1985) com o objetivo de demonstrar a importância do papel da família no desenvolvimento do talento, principalmente na infância. Segundo a mesma autora, raramente as informações de diferentes fontes foram contraditórias. Depoimentos sobre a rotina diária da família, hábitos de trabalho e lazer revelaram esses pais como pessoas ativas e trabalhadoras. Para eles, fazer o melhor, seja qual for a tarefa, é o mais importante; ou seja, realizar o melhor que 
puder. Por isso, alguns desses pais podem ser considerados "perfeccionistas", devido a uma expectativa de atingir o mais alto nível.

De acordo ainda com Sloane (1985), podemos assim resumir suas conclusões:

1 - O compromisso dos pais de usar o tempo produtivo para realizar o melhor que for possível fica evidente nos valores que transmitem a seus filhos. Geralmente discutem a importância de tentar o melhor através do trabalho árduo, controlam os trabalhos de casa das crianças e os estudos instrumentais. Além disso, demonstram uma certa avidez para fornecer oportunidades educacionais extra escolares, embora seletivos na escolha das aulas que desejam.

2 - Para estes pais, a escolha dos professores é também uma questão bastante relevante: procuram professores que apresentem o perfil "certo", com características de personalidade que demonstrem interesse pelos filhos, geralmente escolhidos entre os mais conceituados. Comparecem pelo menos às primeiras aulas para se certificarem de que selecionaram o professor certo e, caso não aprovem as técnicas ou a personalidade do professor, imediatamente tratam de investigar um outro,

3 - Os pais entendem que, para desenvolver o talento, a prática diária é muito importante e não deve ser negligenciada. A maioria dos pais dos pianistas monitoram a quantidade diária da prática em casa; em geral, as crianças não podem sair para brincar enquanto não cumprem o esquema estabelecido. $\mathrm{O}$ estudo é sempre prioritário e deve ser realizado diariamente.

4 - Os pais aplaudem e encorajam os esforços dos filhos e, não raro, envolvem-se no estudo a ponto de poder detectar erros ou sugerir alguma ideia nova musical. A família compartilha atividades em conjunto, como, por exemplo, indo e voltando das aulas, pais e filhos falando e discutindo assuntos relacionados à prática, onde a importância de objetivos e autodisciplina são evidentes nas regras e expectativas relacionadas às aulas e estudo .

Portanto, após alguns anos de instrução formal, e com o apoio dos pais, esses indivíduos desenvolvem-se solidamente. Na análise de Bloom (1985, p. 518523), a mudança para o próximo período do desenvolvimento do talento é frequentemente assinalado pela substituição do antigo professor por um mais 
competente ou exigente. Aulas passam a ser mais difíceis e o estudo, mais intenso. A família focaliza maior atenção, tempo e conhecimento sobre o desenvolvimento do talento dos filhos. Geralmente nesta fase, as aulas são mais caras e podem localizar-se longe da residência. Os pais arranjam recitais, pagam taxas e de um modo geral, fazem um sacrifício maior para garantir a qualidade de instrução para a criança. As aulas, estudo e competições dominam a rotina da família, enquanto que as férias, fins-de-semana e atividades sociais giram em torno do interesse musical, não medindo esforços quanto às despesas com viagens e equipamentos que, no caso dos pianistas são representados por partituras e pianos melhores.

\section{5 - O PAPEL DA FAMÍLIA NA FORMAÇÃO COMPETENTE DE RECONHECIDOS PIANISTAS}

Analisando o perfil biográfico de pianistas de diferentes nacionalidades e épocas, observamos e constatamos a presença de grande parte dos argumentos e situações descritas neste trabalho. Foram selecionados de forma randômica oito pianistas, embora a consulta tenha atingido um número bem maior. 0 denominador comum foi o nível de excelência e desempenho artístico, cuidadosamente observados em cada indivíduo. Tais informações foram obtidas em periódicos especializados e reforçam a importância e papel da família na formação competente de pianistas, fortalecendo os princípios de formulação desse trabalho.

5.1 - Vlado Perlemuter (1904-2002) nascido na Lituânia era filho de um cantor litúrgico. A família mudou-se para Paris, ainda quando criança, sendo conduzido para a classe do renomado pianista Moritz Moszkowski, de quem herdou, segundo seu próprio depoimento, os alicerces de sua técnica. Aos 13 anos ingressou na classe de Alfred Cortot no Conservatório de Paris, recebendo um primeiro Prêmio em 1919. Percorreu brilhante carreira como solista e professor, apesar do difícil período correspondente à $2^{a}$ guerra, quando teve que fugir para a Suíça'.

\footnotetext{
${ }^{1}$ Timbrell, 2002, p. 8-9.
} 
5.2 - Vanessa Wagner (1974-), nasceu em Rennes, França. Entrevistada para a mesma revista em 2002 sobre sua promissora carreira pianística, declara:

Meus pais são leitores por vocação, e naturalmente, desde cedo, eu cresci em um ambiente aberto a todas as artes: literatura..., pintura, escultura e música...estimularam bastante minha imaginação e mesmo ainda quando criança contava meus próprios contos de fantasia (Elger Niels - ibidem Nov/Dec, 2002, p. 50-53, v. 51-tradução nossa) ${ }^{2}$.

Foi introduzida no piano quando sua casa recebeu o piano Gaveau da avó. Com oito anos ingressou no Conservatório de Rennes para estudar com Pierre Froment, aluno e, por algum tempo, assistente de Alfred Cortot, um dos mais renomados pianistas e professores na França (Niels, 2002, p. 50-53).

5.3 - Jenö Jandó (1952-) - pianista húngaro, famoso pelas melhores vendas de discos da conhecida Companhia Naxos. Com mais de 100 discos gravados para a Naxos em 2001, ano da publicação de sua entrevista no periódico consultado, Jandó apresenta enorme variedade de repertório, desde os clássicos até os contemporâneos. Sua mãe era pianista profissional e seu pai, professor de canto, além de maestro do coro local. Desde tenra idade, a bagagem vocal da família influenciou-o em termos de interpretação instrumental. A mãe costumava pedir que tocasse as mesmas canções em diferentes tonalidades e, através dessa prática, conseguia reconhecer as relações intervalares e instintivamente entendia as tonalidades. Recebeu orientação pedagógica no Conservatório Pécs, na cidade do mesmo nome, na Hungria, aprendendo Czerny, Schubert e Bach, ao lado dos compositores clássicos vienenses (Talbot, 2001, p. 28-31).

5.4 - Lise de la Salle - Pianista francesa nascida em 1988, laureada em vários concursos internacionais, afirma em seu depoimento que não consegue lembrar sua vida sem um piano. Cresceu em uma família, onde a arte, especialmente música e pintura eram muito importantes. Seu bisavô foi dono de uma galeria de arte em Paris e sua bisavó, pianista na Rússia e aluna de

\footnotetext{
2 "My parents are both literary by inclination, so naturally from the start I was brought up in an environment open to all arts - literature ..painting, sculpture and music. They very much stimulated my imagination ... and as a child I began to recount my own fantasy-tales"
} 
Tchaikovsky. Refere-se ao seu professor Pascal Nemirovski como um magnífico músico, cujos ensinamentos, em grande parte herdados de Josef Llé vinne ${ }^{3}$, enriqueceram seu conhecimento e nível artístico-musical (Cutts, 2003, p. 59).

6.5 - Dubravka Tomsiç - Nasceu em 1940, Ljubljana, Slovenia, mas recebeu sua educação musical nos Estados Unidos. Apresentou-se com importantes orquestras e festivais tanto nos Estados Unidos como Europa, além de participar de júris em Concursos Internacionais de piano. Sua discografia é considerável, abrangendo especialmente compositores clássicos e românticos. Segundo seu depoimento, sua mãe nutria grande amor pela música e costumava tocar e cantar canções folclóricas particularmente para ela, que, espontaneamente tentava reproduzi-las no piano. Por esse motivo a mãe aconselhou-se com músicos, o que levou a pianista a iniciar seus estudos aos 4 anos; aos 5, deu seu primeiro recital. Alguns anos depois, conseguiu uma bolsa especial de estudos na Julliard School, uma das mais conceituadas escolas de música dos estados Unidos (Uszler, 1998, p. 28-32).

5.6 - A família Hambourg, que abrange três gerações de pianistas: Mikhail, professor do Conservatório de Moscou e aluno de Nicholas Rubinstein; Mark, filho de Mikhail e aluno de Leschetizky; e Michal, filha de Mark e também considerada uma excelente pianista. Entrevistada em 1995, Michal assim se expressou quanto ao ambiente doméstico em que cresceu:

... desde as minhas mais antigas memórias, nossa casa vivia cheia de música e músicos... À noite, após o jantar, todos tocavam música de câmera e eu apenas tinha que fechar meus olhos para sentir a experiência da intensa vida e energia daquele cenário musical.. Muitos dos excelentes músicos daqueles dias eram amigos dos meus pais: Busoni, Rubinstein, ....aquelas noites eram vibrantes com especiais conversas centradas em volta de um magnífico depósito de ideias musicais herdadas ${ }^{4}$. (tradução nossa)

\footnotetext{
3 Pianista russo (1874-1944) que emigrou para os Estados Unidos em 1919, onde foi professor da Julliard School.

${ }^{4}$ Evans, 1998, p. 33-36. "From my earliest memories, our home was full of music and musicians....In the evenings, after dinner, everyone played chamber music and I have only to close my eyes to feel the experience of intense life and energy in that musical scene. Many of the great musicians of those days were my parent's friends: Busoni,... Rubinstein...
} 
5.7 - Leonard Stein (1916-2004), pianista americano assistente de Arnold Schoenberg após 1935, encontrava-se ainda em plena atividade aos 84 anos. Seu pai, cantor de liturgia judaica, era conhecido pela qualidade de sua voz, e cuja arte era basicamente voltada para o estilo semítico/judaico com acentuada ênfase nos melismas. Leonard Stein declara que, como na maioria das famílias judias, havia um piano em casa. Ele, que iniciou seus estudos aos cinco anos, e quatro de seus irmãos estudaram música. Sua professora, segundo o próprio Stein, forneceuIhe sólida base musical. Cresceu em Los Angeles, por ele considerado o maior centro americano para os artistas que chegavam da Europa ${ }^{5}$.

5.8 - Nelson Freire (1944-) - pianista brasileiro nascido em Boa Esperança, Minas Gerais e reconhecido internacionalmente como um dos grandes pianistas dos séculos XX e XXI. Sua família mudou-se para o Rio de Janeiro para que pudesse ter melhor formação e estudar com competentes professores, tendo sido aluno de Nise Obino e Lucia Branco. Finalista do Concurso Internacional de Piano no Rio de Janeiro aos 13 anos de idade, foi contemplado com uma bolsa de estudos para Viena. Em Londres obteve o prêmio Medalha Dinu Lipatti e em Lisboa foi o primeiro prêmio do Concurso Internacional Vianna da Motta ${ }^{6}$.

\section{6 - CONSIDERAÇÕES FINAIS}

Observamos neste trabalho exemplos de como as famílias, envolvidas em atividades artístico-musicais, investem no sucesso dos filhos ao escolher professores do mais alto nível profissional e artístico. Bem sucedidos músicos e seus respectivos pais aplicam tempo, energia e finanças para realizar seus objetivos.

De que forma estes artistas puderam manter seu interesse por tanto tempo antes de alcançarem excelentes níveis de performance? Interroga Sosniak

Those evenings were vibrant with a special kind of conversation, centered around a great tank of inherited musical ideas."

${ }^{5}$ Blomster, Wes. Piano \& Keyboard. San Anselmo, CA: Sparrow Hawk Press, v. 23-24, p. 22-30.

${ }^{6}$ Disponível em www.nelsonfreire.com. Acesso em 13 de março de 2012. 
(1985). Anos de perseverança em um mesmo tipo de atividade não é nada comum em indivíduos entre cinco e 20 anos, ele mesmo responde.

Primeiramente, é principalmente o interesse da família que motiva a criança ou o jovem comprometido com a atividade artística. Geralmente esses pais são mais envolvidos com a educação musical que a maioria, são firmes na exigência do estudo diário e as crianças não tem escolha, gostando ou não do trabalho.

Muitos dos pianistas entrevistados para o trabalho de Sosniak declararam que os pais costumavam avisar que, se os filhos não estudassem devidamente, interromperiam as aulas, parecendo indicar que o controle e monitoramento das crianças trazem relevantes consequências para o desenvolvimento de suas habilidades artísticas. Insistindo na prática diária, esses pais ensinam disciplina e consolidam hábitos, que, uma vez estabelecidos, dificilmente se modificam.

Como foi parcialmente demonstrado, o interesse, a participação e o apoio dos pais contribuem para o desenvolvimento do talento dos filhos, proporcionando-lhes ótimos professores, orientando-os numa disciplina regular e convencendo-os da necessidade de um trabalho árduo. Não se pode afirmar que seja o único fator para o sucesso do futuro músico, mas, sem dúvida alguma, é essencial na maioria dos casos.

\section{REFERÊNCIAS}

BLOMSTE, Weis. Piano \& keyboard, vol 23/24. San Anselma: Sparrow hark Press, s/d.

BLOOM, Benjamin. S. Generalizations About Talent Development. In: BLOOM, Benjamin S. (edit). Developing Talent in Young People. New York: Ballantine Books, 1985, p. 507-549.

CHAFFIN, Roger and LEMIEUX, Anthony F. General Perspectives on Achieving Musical Excellence. In: WILLIAMON, Aaron (edit). Musical Excellence. New York: Oxford University Press, 2011, p. 19-39

CUTTS, Chloe. International Piano. London: Orpheus Publication, p. 59, Sept/Oct 2003.

GEMBRIS, Heiner \& DAVIDSON, Jane W. Environmental Influences. In: PARNACUTT, Richard and MACPHERSON, Gary E. (edit), The Science \& 
Psychology of Music Performance. Oxford: Oxford University Press. 2002 p. 1720.

KEMP, Anthony E. \& MILLS, Janet. Musical Potential. In: PARNACUTT, Richard and MACPHERSON, Gary E. (edit), The Science \& Psychology of Music Performance. Oxford University Press, 2002, p. 3-16.

LECANUET, Jean-Pierre. Prenatal auditory experience. In: DELIÈGE, Irène and SLOBODA, John (eds). Musical beginnings: origins and development of musical competence. Oxford: Oxford University Press, 1996, p. 03-34.

MCPHERSON, Gary E. \& ZIMMERMAN, B, J. Self-regulation of musical learning: A social cognitive perspective. In: R. Colwell \& C. Richardson (edit), The New Handbook of Research on Music. Oxford: Oxford University Press, 2002, p. 327347.

NIELS, Elger. International Piano. London: Orpheus Publication, v. 51, p. 50-53, Nov/Dec., 2002.

SLOANE, Kathryn D. Home Influences on Talent Development. In: BLOOM, Benjamin S. (edit) Developing Talent in Young People. New York: Ballantine Books, 1985, p. 439-440.

SLOBODA, John and DAVIDSON, Jane. The Young Performing Musician. In: DELIÈGE, Irène and SLOBODA, John (eds). Musical beginnings: origins and development of musical competence. Oxford: Oxford University Press, 1996. p.176-190.

SOSNIAK, Lauren A. Learning to be a concert pianist. In: BLOOM, Benjamin S. (edt) Developing Talent in Young People. New York: Ballantine Books, 1985, p. 19-67.

TALBOT, Joanne. International Piano Quarterly. New Jersey: Orpheus Publication Limited, v. 28, p. 28-31, Spring 2001.

TIMBRELL, Charles. International Piano. London: Orpheus Publication, v. 9, p. 8-9Nov/Dec. 2002.

USZLER, Marienne. Piano \& Keyboard. San Anselmo, CA: Sparrow Hawk Press, v. 29, p. 28-32, March/April 1998. 